\title{
Environmental behaviour of semi-open spaces in Mediterranean vernacular architecture. The case of rural traditional dwellings of Cyprus
}

\author{
E. Malaktou ${ }^{1}$, M. Philokyprou ${ }^{1}$, A. Michael ${ }^{1}$ and A. Savvides ${ }^{1}$ \\ ${ }^{1}$ Department of Architecture \\ University of Cyprus
}

Phone number: + 357 22895412, e-mail: meleni@ucy.ac.cy, mphiloky@ucy.ac.cy, aimilios@ucy.ac.cy, als@ucy.ac.cy

\begin{abstract}
The environmental advantages of semi-open spaces have long been recognized. Such spaces have the ability to mediate outdoor temperatures through the reduction of solar heat gains. Nevertheless, such claims lack quantitative validation since the majority of researches on semi-open spaces have been based on qualitative assessments. In order to address this issue, the present study focuses on the environmental study of traditional semi-open spaces of Cyprus through onsite air temperature, relative humidity and solar radiation measurements during different seasons of the year. Drawing from the onsite measurements, the environmental behaviour of semi-open spaces in relation to different orientations and architectural layouts is discussed, while the environmental effect of outdoor climatic variables is additionally investigated. The above mentioned parameters are considered to be the determining factors affecting the thermal behaviour of a semi-open space. The findings of this study indicate that semi-open spaces may result in a variety of microclimatic conditions which can create more thermally adaptive environments. The assessment of the microclimate of traditional semi-open spaces could help towards the evaluation of such spaces as authentic bioclimatic elements and contribute to their proper conservation in the rehabilitation of traditional buildings.
\end{abstract}

\section{Key words}

Semi-open spaces, Mediterranean climate, vernacular architecture, environmental behaviour, onsite measurements

\section{Introduction}

Semi-open spaces are significant features of Mediterranean dwellings that respond to the mild climatic conditions and the lifestyle of the locals. Such structures can be found in several public and domestic buildings in different historic periods. In the ruins of the ancient Greek settlement of Olynthos, many dwellings of the Classical period incorporate a colonnade semi-open area bordering the courtyard, called pastas, usually south oriented to offer protection from intense solar radiation [1]. Moreover, in the domestic architecture of the Cycladic island of Delos several peristyle courts were excavated dating back to the Late Hellenistic period. Peristyle courts were open to light and air, assuring natural daylight penetration and ventilation to the indoor spaces. The Hellenistic peristyle court later became a distinctive feature of dwellings during the Roman period, and comprised a vital element of Roman villas, such as those in Pompeii [2]. Over the centuries, semi-open spaces took various forms and were applied extensively in the vernacular architecture of the Mediterranean.

Located in the Eastern Mediterranean region, Cyprus itself has a long tradition of semi-open spaces - namely the remains of peristyle courts of Roman villas, the Medieval (Latin) pass-through vaulted semi-open spaces which provided direct access from the street to the internal courtyard, as well as a number of pointed-arches defining semi-open spaces - in one or more internal elevations of dwellings. Similar design solutions for semi-open spaces had, until recently, been followed in the vernacular architecture of Cyprus since such spaces respond well to the hot and semi-arid type of climate of the island.

As a transitional zone between indoors and outdoors, semi-open spaces have the ability of mediating outdoor temperatures and improving the thermal comfort of the interior - by reducing solar heat gains - while, at the same time, contributing to filtering intense daylight and providing protection from rain [3]. Apart from their essential bioclimatic contribution, semi-open spaces serve as circulation spaces and have been extensively exploited for household and agricultural activities, as well as, for social gatherings. Although they respond well to a series of social, climatic and functional design concerns, semiopen spaces have been underestimated in contemporary domestic architecture mainly due to the limited consideration of the local context in the design process. Up until now, the study of semi-open spaces from an environmental perspective has not been very extensive and past studies have mainly concentrated on typological aspects [4]. This study attempts to investigate the interrelation between semi-open space orientation and architectural layout with microclimatic conditions and the effect of outdoor climatic variables and season shifts with regards to the thermal behavior of semi-open spaces. The aim of this research is to help towards the proper 
preservation of such spaces during the rehabilitation of existing buildings and to the drafting of recommendations in order to optimize the environmental performance of these spaces in contemporary buildings.

\section{Background}

Several studies devoted to the understanding of the environmental performance of semi-open spaces have shown correlations between their architectural layout and orientation. A study of six different semi-open spaces in Yokohama, Japan confirmed that the level of exposed area correlates well with air temperature and relative humidity [5]. Moreover, two studies, the first undertaken in Sifnos, Greece and the second involving the city of Cambridge, U.K. establish that the degree of enclosure is related to the average temperature fluctuation and the maximum temperature [6]. The study provides evidence that semiopen spaces with the same degree of enclosure but larger in volume demonstrate higher temperature fluctuations. Other researchers [7] indicate that a change in the orientation of a semi-open space, open at its ends constant, has an effect on its environmental behaviour. More specifically, it has been found that an east-west oriented semi-open space causes larger diurnal temperature fluctuations than a north-south oriented space (by $3.5^{\circ} \mathrm{C}$ ). This is attributed to the impact of solar radiation which is strongly related to orientation [4]. A north-south oriented semi-open space is more protected from direct solar radiation than an east-west oriented space, due to the different solar altitude angle [8]. Apart from orientation and architectural layout, materials also have a considerable impact on the environmental performance of semi-open spaces [8]. Onsite measurements in London and Cardiff indicate that arcades with less glazed surface on the roof achieve higher reductions in temperatures during summer [8]. Nevertheless, the references found in the review of literature on the relation between one or more semi-open spaces environmental variables and outdoor environmental variables are scarce. The study of Nakano \& Tanabe (2004) [9] showed a strong linear correlation between (a) air temperatures of semi-open spaces and outdoor air temperatures and (b) humidity ratio of semi-open spaces and outdoor humidity ratio.

\section{Methodology}

\section{A. Onsite measurements}

The proposed research methodology is based on case study monitoring of three selected traditional dwellings in the lowland traditional village of Pera Orinis, Cyprus (Fig. 1). Specifically, onsite air temperature measurements have been performed at four semi-open spaces, i.e. Case Study $\mathrm{A}_{1}$, Case Study $\mathrm{A}_{2}$, Case Study B and Case Study C, and one indoor high-mass reference space, i.e. Case Study $\mathrm{A}_{0}$ (Fig. $1 \& 2$ ). The semi-open spaces under examination vary in terms of their orientation and architectural characteristics. Data loggers for air temperature measurements were placed $1.5 \mathrm{~m}$ above floor level and were protected from direct solar radiation. Measurements were taken in different seasons - namely during August

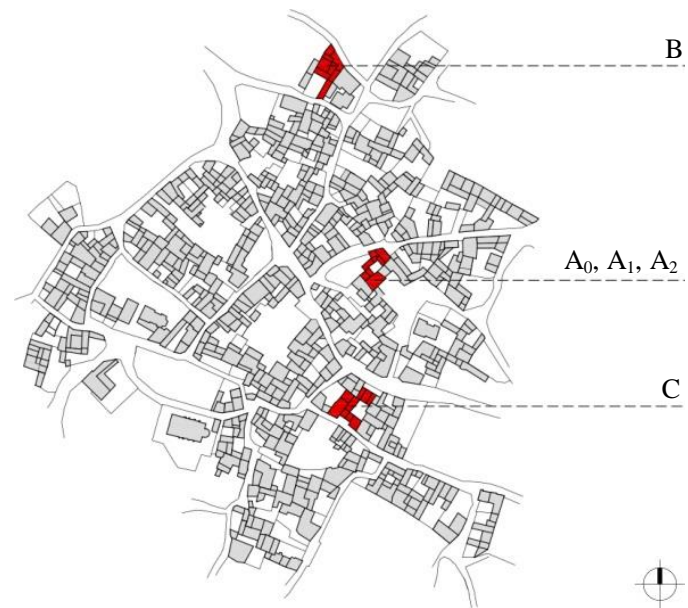

Fig. 1. Map of Pera Orinis settlement indicating the case study buildings

(hot, summer period), October (mid-season period) 2014 and January (cold, winter period) 2015. Moreover, measurements of outdoor climatic conditions (global solar radiation, relative humidity and air temperature) were carried out using a VantagePro weather station. Initially, analysis of onsite measurements were undertaken in order to discuss the environmental behaviour of semi-open spaces in relation to orientation and architectural layout. Subsequently, the study examines the environmental effect of the transformation of semi-open spaces into indoor spaces by the addition of glazing as this constitutes a common design intervention applied in the rehabilitation of traditional buildings. The last section of the study presents how outdoor climatic conditions affect the environmental behaviour of semi-open spaces in different seasons. Specifically, the research correlates daily maximum temperatures of semi-open spaces with daily mean global solar radiation, minimum outdoor relative humidity and maximum outdoor temperatures.

\section{B. Description of case study spaces}

The selected semi-open spaces are typical in terms of their construction building materials and traditional typology. There are two distinctly different typologies of semi-open spaces in the traditional architecture of Cyprus: a longitudinal living space attached to the main rooms called iliakos and a pass through entrance called portico [10]. The design and evolution of iliakos and portico in domestic architecture -especially in the lowland regions - is linked to climatic parameters. The climate of lowland regions is characterized by mild winters, hot and dry summers, intense solar radiation and extended periods of sunshine. These conditions turn the shaded and ventilated spaces into favoured spots.

Iliakos is a semi-open space configured by a series of stone-built pointed arches or by a timber beam and post structure. Iliakos faces the internal courtyard and it is usually open on one side - the longer one. It has a wide frontage and it is shallow in plan. According to bibliographical references [10], the predominant orientation of iliakos is towards the south for better solar exploitation. Nevertheless, other authors [11] report that 
$\mathrm{A}_{1}$.

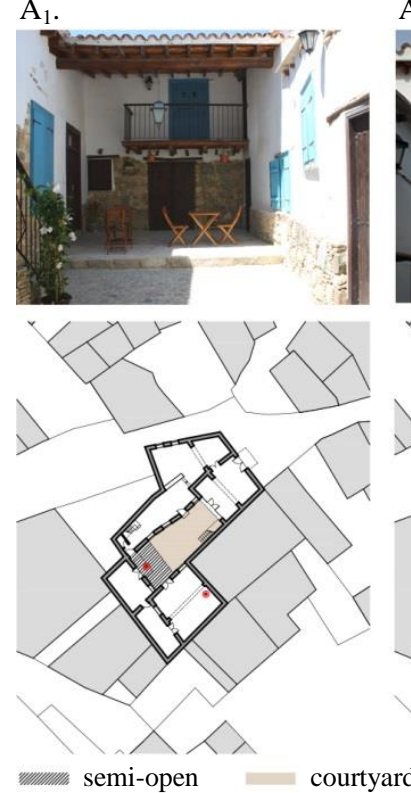

$\mathrm{A}_{2}$.
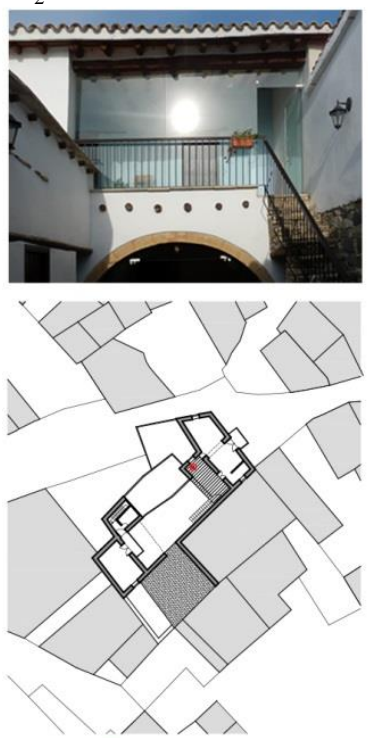

B.
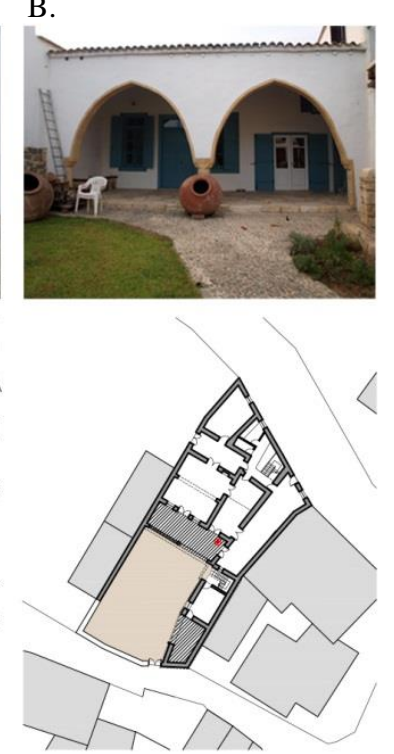

C.
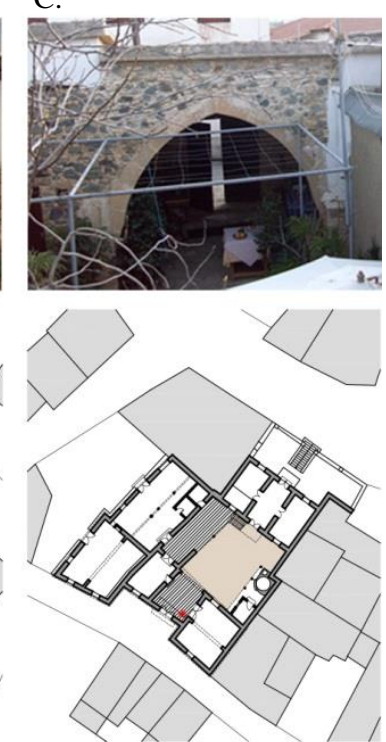

Fig. 1. Images and plans representing semi-open spaces where measurements were taken, $A_{1}$. Case Study $A_{1}$ and indoor reference space $\mathrm{A}_{0}, \mathrm{~A}_{2}$. Case Study $\mathrm{A}_{2}, \mathrm{~B}$. Case Study B and C. Case Study C

its prevailing orientation is towards the east to offer adequate solar penetration during the cold season. The portico is a pass-through transitional space which links the street to the internal courtyard. It has a narrow frontage and a deep plan layout. It is permanently open on one side, while its opposite side is configured by a double door. The portico is a distinctive environmental feature, while its openings at the opposite ends of the space and its elongated configuration, allow for enhanced natural ventilation and shading.

Case Study $\mathrm{A}_{1}$, Case Study $\mathrm{A}_{2}$ and Case Study $\mathrm{B}$ are representative of the iliakos typology (Fig. 2). Case Study $\mathrm{A}_{2}$ has been converted into an indoor space by the addition of fixed glazing. Case Study $\mathrm{A}_{1}$ and Case Study $\mathrm{A}_{2}$ are defined by a timber beam structure, while Case Study B by two pointed arches. Case Study C is representative of the portico typology (Fig. 2). All four spaces under examination are enclosed by high-mass adobe walls and tiled roofs. Tiled roofs are configured by multiple layers, made with timber rafters which are covered with reed battens or matting, earth and tiles.

\section{Results and discussion}

Based on the onsite measurements, the main parameters examined are: the orientation, the degree of enclosure (DoE), i.e. the ratio of the total surface areas over the exposed surface areas (openings) of the semi-open spaces, including glazed surfaces. The analysis also includes how outdoor climatic variables, and the different seasons, affect the microclimatic conditions within these spaces using correlation studies.

\section{A. Orientation}

In order to examine the effect of orientation on microclimatic conditions, two semi-open spaces (Case Study $\mathrm{A}_{1}$ and Case Study B) constructed using the same materials, facing an internal courtyard and having a quite similar DoE (4.4 and 4.5) have been selected (Fig. 1). The two cases differ in orientation - Case Study B faces southwest and Case Study $\mathrm{A}_{1}$ northeast. It is noted that varying results may also be attributed to other factors such as the surrounding building forms and massing, as well as to the enclosure of the internal courtyard. Nevertheless, in these case studies, orientation is considered to be the main factor affecting microclimatic conditions. Throughout the examined seasons, Case Study B presents higher mean maximum temperatures compared to Case Study $\mathrm{A}_{1}$, i.e. $3.9{ }^{\circ} \mathrm{C}$ higher mean maximum temperature in August, 4.9 ${ }^{\circ} \mathrm{C}$ in October and $4.1^{\circ} \mathrm{C}$ in January (Table I). Moreover, Case Study B exhibits larger mean diurnal temperature fluctuations, i.e. $4.7{ }^{\circ} \mathrm{C}$ larger mean diurnal temperature fluctuations in August, $5.3{ }^{\circ} \mathrm{C}$ in October and $4.0{ }^{\circ} \mathrm{C}$ in January. The results indicate that the south-oriented semiopen space exhibits generally higher temperatures and diurnal temperature fluctuations compared to the northoriented one. This variation in temperatures of semi-open spaces with different orientation is mainly attributed to the impact of direct solar radiation. Moreover, throughout the examined seasons, Case Study B exhibits maximum temperatures above maximum outdoor temperatures, while Case Study $A_{1}$ exhibits maximum temperatures below maximum outdoor temperatures. This indicates that semi-open spaces with southern orientation could provide a warmer space during a cold, sunny winter day while spaces with northern aspect could offer greater thermal stability and a cooler space during a hot, summer day. These results agree with other studies [4, 8] that link orientation with the thermal performance of semi-open spaces. Mean minimum temperatures are lower in Case Study B, i.e. $0.7^{\circ} \mathrm{C}$ lower mean minimum temperature in August, $0.4{ }^{\circ} \mathrm{C}$ in October and $0.1^{\circ} \mathrm{C}$ in January (Table I). It is interesting to note that despite the relatively large difference in mean maximum temperatures between the case study spaces, the difference in mean minimum temperatures is small. The slight decrease of mean minimum air temperatures in Case Study B compared to Case Study $\mathrm{A}_{1}$ could be related to the wind conditions. 
Table I. Air temperatures recorded in different seasons

\begin{tabular}{|c|c|c|c|c|c|c|c|c|c|c|c|}
\hline & \multirow[b]{2}{*}{ Orient. } & \multirow{2}{*}{$\begin{array}{c}\text { Symbol of } \\
\text { case study } \\
\text { space }\end{array}$} & \multirow{2}{*}{$\begin{array}{c}\text { Width } \\
\text { (m) }\end{array}$} & \multirow[b]{2}{*}{$\begin{array}{l}\text { Height } \\
\text { (m) }\end{array}$} & \multirow{2}{*}{$\begin{array}{l}\text { Length } \\
\text { (m) }\end{array}$} & \multirow[b]{2}{*}{$\begin{array}{l}\text { Volume } \\
\left(\mathrm{m}^{3}\right)\end{array}$} & \multirow[b]{2}{*}{ DoE } & \multicolumn{4}{|c|}{ Air Temperature $\left({ }^{\circ} \mathrm{C}\right)$} \\
\hline & & & & & & & & $\begin{array}{c}\text { Mean } \\
\text { avg }\end{array}$ & $\begin{array}{c}\text { Mean } \\
\max \end{array}$ & $\begin{array}{c}\text { Mean } \\
\text { min }\end{array}$ & $\begin{array}{l}\text { Mean } \\
\text { fluct. }\end{array}$ \\
\hline & & & & & \multicolumn{7}{|c|}{ August } \\
\hline Outdoor & - & & - & - & - & - & - & 27.7 & 34.9 & 21.3 & 13.6 \\
\hline Indoor Case Study $\mathrm{A}_{0}$ & & - & 6.0 & 4.5 & 6.0 & 162 & - & 29.4 & 30.1 & 28.7 & 1.4 \\
\hline Case Study $A_{1}$ & $\mathrm{NE}$ & + & 3.0 & 5.5 & 4.8 & 79.2 & 4.4 & 29.4 & 34.0 & 25.5 & 8.5 \\
\hline Case Study $\mathrm{A}_{2}$ & SW & & 2.2 & 3.0 & 5.3 & 35.0 & 5.7 & 32.3 & 39.6 & 28.5 & 11.1 \\
\hline Case Study B & SW & 0 & 2.9 & 4.3 & 8.9 & 111 & 4.5 & 29.8 & 37.9 & 24.7 & 13.2 \\
\hline \multirow[t]{2}{*}{ Case Study C } & $\mathrm{NE}$ & $\mathrm{X}$ & 4.4 & 3.9 & 4.1 & 70.4 & 8.0 & 28.7 & 32.6 & 25.5 & 7.1 \\
\hline & & & & & \multicolumn{7}{|c|}{ October } \\
\hline Outdoor & - & & - & - & - & - & - & 18.3 & 24.4 & 13.5 & 10.9 \\
\hline Indoor Case Study $\mathrm{A}_{0}$ & & - & 6.0 & 4.5 & 6.0 & 162 & - & 22.4 & 22.7 & 22.0 & 0.7 \\
\hline Case Study $A_{1}$ & $\mathrm{NE}$ & + & 3.0 & 5.5 & 4.8 & 79.2 & 4.4 & 19.6 & 23.3 & 16.8 & 6.5 \\
\hline Case Study $\mathrm{A}_{2}$ & SW & & 2.2 & 3.0 & 5.3 & 35.0 & 5.7 & 23.9 & 30.7 & 20.8 & 9.9 \\
\hline Case Study B & SW & 0 & 2.9 & 4.3 & 8.9 & 111 & 4.5 & 20.8 & 28.2 & 16.4 & 11.8 \\
\hline Case Study C & & & & & \multicolumn{7}{|c|}{ January } \\
\hline Outdoor & - & & - & - & - & - & - & 8.8 & 13.3 & 5.0 & 8.3 \\
\hline Indoor Case Study $\mathrm{A}_{0}$ & & - & 6.0 & 4.5 & 6.0 & 162 & - & 13.1 & 13.3 & 12.9 & 0.4 \\
\hline Case Study $\mathrm{A}_{1}$ & $\mathrm{NE}$ & + & 3.0 & 5.5 & 4.8 & 79.2 & 4.4 & 9.8 & 12.6 & 7.6 & 5.0 \\
\hline Case Study $\mathrm{A}_{2}$ & SW & & 2.2 & 3.0 & 5.3 & 35.0 & 5.7 & 15.5 & 21.3 & 13.0 & 8.3 \\
\hline Case Study B & SW & 0 & 2.9 & 4.3 & 8.9 & 111 & 4.5 & 10.9 & 16.7 & 7.5 & 9.2 \\
\hline Case Study C & $\mathrm{NE}$ & $\mathrm{x}$ & 4.4 & 3.9 & 4.1 & 70.4 & 8.0 & 9.4 & 11.5 & 7.6 & 3.9 \\
\hline
\end{tabular}

The prevailing western winds in the region may increase the rate of heat loss in Case Study B during night-time due to its southwest orientation.

\section{B. Degree of enclosure}

In order to examine the influence of the architectural layout on microclimatic conditions, two semi-spaces were monitored (Case Study $A_{1}$ and Case Study C) constructed with the same materials, oriented northeast, facing an internal courtyard and having DoE 4.0 (Case Study $\mathrm{A}_{1}$ ) and 8.0 (Case Study C). These measurements show that Case Study $\mathrm{A}_{1}$, exhibits higher mean maximum temperatures, i.e. $1.4{ }^{\circ} \mathrm{C}$ higher mean maximum temperature in August, $1.5^{\circ} \mathrm{C}$ in October and $1.1^{\circ} \mathrm{C}$ in January (Table I). Moreover, Case Study $\mathrm{A}_{1}$ presents larger mean diurnal temperature fluctuations, i.e. $1.4{ }^{\circ} \mathrm{C}$ higher mean diurnal temperature fluctuation in August, $1.5{ }^{\circ} \mathrm{C}$ in October and $1.1{ }^{\circ} \mathrm{C}$ in January. These results indicate that the more enclosed the semi-open space is (high DoE) the less exposed it becomes to outdoor climatic conditions, exhibiting therefore, a thermal performance similar to an indoor space. These findings are in line with other studies $[4,6,7]$ indicating that semiopen spaces with high DoE achieve greater moderation of the external thermal inflows for a given orientation. Of interest is also the fact that mean minimum temperatures in the two spaces under investigation are identical in August, October and January. Case Study $\mathrm{A}_{1}$ thus results in greater heat losses during night-time (considering that it exhibits higher mean maximum temperatures). Due to the fact that Case Study $A_{1}$ is less enclosed, more radiation is allowed to escape into the night sky, which results in a greater decrease of the temperatures.

\section{Conversion of semi-open spaces into indoor spaces}

A comparative analysis was performed between the temperatures of a southwest oriented semi-open space converted into an indoor space by the addition of glazing (Case Study $\mathrm{A}_{2}$ ) and the temperatures of a southwest oriented semi-open space which has preserved its original form (Case Study B). Throughout the examined seasons, Case Study $\mathrm{A}_{2}$ exhibits significantly higher mean maximum temperatures, i.e. $1.7{ }^{\circ} \mathrm{C}$ higher mean maximum temperatures in August, $2.5{ }^{\circ} \mathrm{C}$ in October and $4.6{ }^{\circ} \mathrm{C}$ in January (Table I). Moreover, compared to the closed room (Case Study $\mathrm{A}_{0}$ ), Case Study $\mathrm{A}_{2}$ exhibits significantly higher mean maximum temperatures, i.e. 9.5 ${ }^{\circ} \mathrm{C}$ higher mean maximum temperature in August, $8.0^{\circ} \mathrm{C}$ in October and $8.0{ }^{\circ} \mathrm{C}$ in January. The results reveal that the large amount of solar heat gains absorbed by the glazed surfaces raises temperatures high above temperatures of high-mass indoor spaces and semi-open spaces. These findings agree with the results reported by Potvin [8]. Large glazed surfaces facing south may cause an adverse thermal effect during the hot, summer period if precautions are not taken with regards to shading and natural ventilation. Nevertheless, during the cold, sunny winter days, spaces with large glazed surfaces facing south could provide comfortable living conditions during daytime. Unsurprisingly, the mean minimum temperatures of Case Study $\mathrm{A}_{2}$ remain higher than the temperature of Case Study B due to the insulation of glazing, i.e. $3.8^{\circ} \mathrm{C}$ higher mean minimum temperature in August, $4.4^{\circ} \mathrm{C}$ in October and $5.5^{\circ} \mathrm{C}$ in January.

\section{Outdoor climatic variables and season}

The research has shown that maximum air temperatures reached in semi-open spaces are directly related to the outdoor climatic variables, while seasonal changes are found to have a significant effect. Based on correlation studies, a very strong linear correlation between maximum daily temperature of the case study spaces and maximum outdoor temperature is found for August, October and January $\left(0.7201<\mathrm{R}^{2}<0.9638\right)$ (Fig. 3A). These results 
confirm the findings of other studies [9] relating outdoor temperatures with temperatures of semi-open spaces. The lower inclination of the lines in August indicates that maximum outdoor temperatures cause lower elevation of the maximum temperatures in semi-open spaces during the hot, summer period. Moreover, a very strong linear correlation between daily maximum temperatures of Case Study B (southwest oriented semi-open space) and mean global solar radiation is found in January $\left(\mathrm{R}^{2}=0.8468\right)$, a strong correlation in October $\left(\mathrm{R}^{2}=0.7155\right)$ while no correlation between these two variables is noted in August. A modest correlation is found between the maximum temperatures of the northeast oriented Case Study $\mathrm{A}_{1}$ and Case Study $\mathrm{C}\left(0.5787<\mathrm{R}^{2}<0.6279\right)$ and mean global solar radiation during January, a weak correlation is found in October $\left(0.4051<\mathrm{R}^{2}<0.4505\right)$
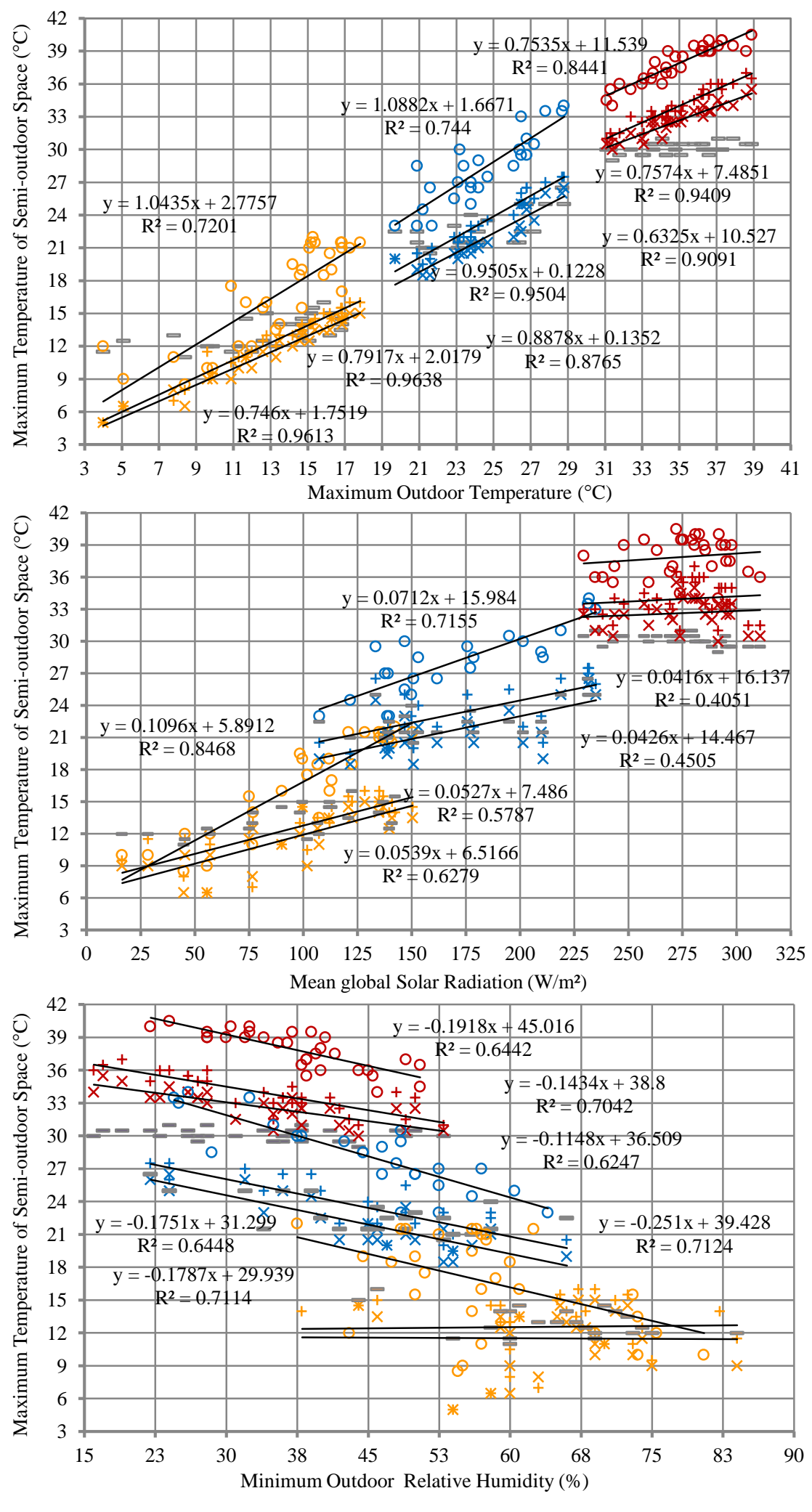

- Case Study A0 + Case Study A1 o Case Study B X Case Study C

Fig. 3 Correlation between maximum temperatures of case study spaces and A. maximum outdoor temperatures, B. mean global solar radiation and C. minimum outdoor relative humidity. Yellow, blue and red colors represent January, October and August respectively 
while no correlation is noted in August (Fig. 3B). The higher inclination of lines in January as opposed to October indicates that the mean global solar radiation causes higher elevation of maximum temperatures in semi-open spaces during the cold, winter period. Finally, the research results show an inverse correlation (modest to strong) between daily maximum temperatures of the case study spaces and the minimum outdoor relative humidity in August $\left(0.6247<\mathrm{R}^{2}<0.7042\right)$ and October $(0.6448<$ $\left.\mathrm{R}^{2}<0.7361\right)$, while no correlation is observed in January (Fig. 3C). In contrast, no correlation is noted between maximum temperatures of the indoor space (Case Study $A_{0}$ ) and outdoor climatic variables (Fig. 3). Case Study $A_{0}$ shows fairly constant and moderated maximum temperatures, especially during August. This behaviour is attributed to the thermal mass effect of the building envelope.

Correlation studies indicate that air temperature is the only outdoor climatic variable that has an all-year effect in maximum temperatures of semi-open spaces. Moreover, this seems to be the major factor affecting maximum temperatures. The impact of solar radiation on maximum temperatures of semi-open spaces is found to be strongly related to orientation and seasonal period. It is confirmed that maximum air temperatures of such spaces with southern orientation are better correlated to mean global solar radiation due to their exposure to direct solar radiation. This is also in line with related literature (e.g. [4]). The variation between maximum air temperature of semi-open spaces and mean global solar radiation gradually decreases from January to October and to August. This may be attributed to two main factors: the solar altitude angle and the thermal inertia of materials. During January, the low solar altitude angle allows deep penetration of direct solar radiation increasing its effect on the maximum temperatures of semi-open spaces. On the contrary, during August the high solar altitude angle protects semi-open spaces from direct solar radiation and reduces its effect on maximum temperatures. Moreover, the high-mass walls enclosing the semi-open spaces have the ability to absorb solar heat, thus minimizing the effect of mean global solar radiation. It is also shown that the effect of outdoor relative humidity on maximum temperatures is linked to the change of seasons. When outdoor relative humidity increases, air temperature decreases. Thus, for a given maximum temperature, a minimum relative humidity occurs. This explains why maximum temperatures of semi-open spaces are correlated with minimum outdoor relative humidity. No correlation is found between the minimum outdoor relative humidity and the maximum temperature of the case study spaces in January and this is most probably due to the effect of rain on humidity levels.

\section{Conclusions}

The outcomes of this study highlight that semi-open spaces can result in a variety of microclimatic conditions of vernacular dwellings, depending on orientation, architectural layout, materiality and season. The investigation of traditional semi-open spaces may contribute to their proper conservation as authentic bioclimatic elements during the conservation of vernacular architecture. Contemporary rehabilitation practices which favour the conversion of such spaces into indoor spaces by the addition of fixed glazing need to be reconsidered so as to address environmental issues. Moreover, the development of a methodology for the assessment and classification of the microclimate of traditional semi-open spaces would contribute to the drafting of general guidelines for the design of semi-open spaces in contemporary buildings resulting in more thermally adaptive domestic environments.

The examination of a larger sample of semi-open spaces will enable the validation of the results presented in this study and will allow the upgrade of the indications given into potential guidelines for a climate-sensitive design of semi-open spaces. Future research will test other parameters involved in the microclimate of semi-open spaces such as wind speed and mean radiant temperature, which are expected to enrich the findings of this study.

\section{Acknowledgement}

The present research is based on the findings of the research program entitled "Implementation of Sustainable Design Elements of Vernacular Architecture in the Rehabilitation of Traditional Buildings and in the Design of New Structures" funded by the University of Cyprus.

\section{References}

[1] Nevett, L. (2001). House and society in the ancient Greek world. Cambridge University Press.

[2] Watkin, D. (2005). A history of Western architecture. Laurence King Publishing.

[3] Potvin, A. (2000). Assessing the microclimate of urban transitional spaces. The 18th Passive and Low Energy (PLEA) Conference. Architecture, City, Environment. Cambridge.

[4] Sinou, M., \& Steemers, K. (2003). Urban space thermal analysis of case studies. Conference of Sustainable Planning and Development.Skiathos: Wessex Insitute of Technology (WIT) Press.

[5] Chun, C., Kwok, A., \& Tamura, A. (2004). Thermal comfort in transitional spaces-basic concepts: literature review and trial measurements. Building and Environment, 39(10), 1187-1192.

[6] Sinou, M. (2007). Design and thermal diversity of semi-enclosed spaces. Cambridgeshire: Melrose Books.

[7] Steemers, K., Ramos, M., \&Sinou, M. (2004). Urban diversity. In K. Steemers, \& M. Steane (Eds.), Environmental diversity in architecture (pp. 85-100). London: Spon Press.

[8] Potvin, A. (1997). The arcade environment. Architectural Research Quarterly, 2(4), 64-79.

[9] Nakano, J., \& Tanabe, S. (2004). Thermal confort and adaptation in semi-outdoor environments. ASHRAE Transactions, 543-553.

[10] Sinos, S. (1976). Review of the Vernacular Architecture of Cyprus. Athens.

[11] Papacharalambous, G. (2001). The Cypriot dwelling. Nicosia: The Cyprus Research Centre. 